\title{
Determination of Hydroxymethylfurfural Content (HMF) in Fresh Bee Honey Produced in Bosnia and Herzegovina (B\&H) by HPLC DAD Method
}

\author{
Harun Kurtagić, Edita Sarić, Nevzeta Abdelfattah and Nađa Murtabegović \\ Federal Institute of Agriculture Sarajevo, Bosnia \& Herzegowina
}

Submission: November 23, 2020; Published: January 19, 2021

*Corresponding author: Harun Kurtagić, Federal Institute of Agriculture Sarajevo, Butmirska cesta 40, 71000 Sarajevo, Bosnia \& Herzegowina

\begin{abstract}
The content of HMF in honey and food of plant origin is the subject of many scientific kinds of research, primary for two reasons, firstly its toxicity, secondly, its appearance in honey and food as indicators of the age of food, its way of storing or processing. In this paper, the results of the intralaboratory validation of HPLC method for determining the content of HMF in honey as well as the results of testing fresh samples of honey produced in BiH in 2018 are given. This method is very similar to the ICH [1] method for honey, while innovation in this study is a ballast materials sedimentation by the Carez I and Carez II reagents. The paper gives the results of method validation of the following parameters: interference, specificity, linearity, LOD (limit of detection), LOQ (limit of quantification), precision, accuracy and measuring range. The measuring range of the method is from $60 \mu \mathrm{g} / \mathrm{kg}$ to $\geq 100 \mathrm{mg} / \mathrm{kg}$ with a coefficient of linearity $\mathrm{r} 2=0,99999$. LOQ of $60 \mu \mathrm{g} / \mathrm{kg} \mathrm{had} \mathrm{a} \mathrm{slightly} \mathrm{higher} \mathrm{value} \mathrm{of} \mathrm{deviation,} \mathrm{but} \mathrm{it}$ has no relevance to the maximum residue level (MRL) value of $40 \mathrm{mg} / \mathrm{kg}$ which is significantly higher. As proof of performance, validation is also accomplished a satisfactory result of the proficiency test. After validation was performed, 21 samples of fresh honey of different biological and geographical origins produced in B\&H were tested: 8 acacia, 4 honeydews, 3 chestnuts, 4 meadows, 1 floral and 1 heather. The obtained results ranged from $0.02 \mathrm{mg} / \mathrm{kg}$ (honey Acacia) to $27.40 \mathrm{mg} / \mathrm{kg}$ (medow).
\end{abstract}

Keywords: Honey; HPLC; Plant origin; Validation; HMF

\section{Introduction}

HMF or 5-(hydroxymethyl) furan-2-carbaldehyde belongs to the furan class, which at the position of 2 formulas has a carbaldehidic group and at the position of the 5 hydroxymethyl functional group [2,3]. It is practically absent in fresh food, but it is forming by a natural process in food containing sugars (especially aldoses and ketosis), and in food that is cooked and baked $[4,5]$. HMF is a natural constituent of honey, so it is also in the fresh bee in traces where its amounts less than $15 \mathrm{mg} / \mathrm{kg}-$ depending on $\mathrm{pH}$-value and temperature and age [6]. Its contents, both in honey and other foods containing sugars, represent an indicator of storage, handling or age of food [7]. The content of HMF in honey is very different and depends on many factors, geographical area, climate, honey varieties, quality of honey and especially by the way of processing, preservation and other. Its forming in food is particularly favorable for the high temperature $\left(25^{\circ} \mathrm{C}-50^{\circ} \mathrm{C}\right)$, low $\mathrm{pH}$, length of food standings, acid hydrolysis of sugar, high moisture content and use of metal containers [8]. Honey storage in temperature $<15{ }^{\circ} \mathrm{C}$ also not stopped increasing of HMF amount, but with lower speed [9]. HMF formation under lower temperature is in correlation with $\mathrm{pH}$, organic acid and water activity [10]. Some recent research shows that there are, also some benefits from HMF for human and bee health, however, undoubtedly it has been proven that there are negative effects both on humans and on bees. Bees that feeding with sugar syrup which has high HMF content, may result in partial extinction of society [11]. In humans, it can lead to mutagenic, carcinogenic and other harmful effects, so that according to international standards, the maximum residues level (MRL) for honey from the continental area is $40 \mathrm{mg} / \mathrm{kg}$ and for honey from the tropical area $80 \mathrm{mg} / \mathrm{kg}$ [1]. For HMF content determination in food different methods are used [1,5,12-15]. Method used in this study is very similar to the ICH [1] method for honey, while innovation is a ballast materials sedimentation by the Carez I and Carez II reagents. This paper gives the results of validation of the HPLC method for determining the contents of HMF in fresh B\&H honey and results of testing of fresh samples of honey different variability and geographical origin from 2018. 


\section{Materials and Methods}

\section{Chemicals}

Carrez I reagent: $15 \mathrm{~g}_{4} \mathrm{Fe}(\mathrm{CN})_{6} \times 3 \mathrm{H}_{2} \mathrm{O}$ - potassium hexacyanoferrate(II) trihydrate (p.a.) dissolved in water and filled up to $100 \mathrm{ml}$ (local supplier); Carrez II reagent: $30 \mathrm{~g} \mathrm{Zn}\left(\mathrm{CH}_{3} \mathrm{COO}\right)_{2}$ $x 2 \mathrm{H}_{2} \mathrm{O}$ - zinc acetate dihydrate (p.a.) dissolved in water and filled up to $100 \mathrm{ml}$ (local supplier); CH2O2 - formic acid concentrated p.a. (J.T. Baker); $\mathrm{C}_{6} \mathrm{H}_{6} \mathrm{O}_{3}$ - 5-(hydroxymethyl) furfural; Lot Num. WXBC5068V (Sigma-Aldrich); Acetonitrile, HPLC purity (JT Baker); Methanol, HPLC purity (JT Baker); Deionized and ultrapure water (manufactured in the laboratory).

\section{Equipment and accessories}

Micropipettes calibrated (Eppendorf); HPLC with DAD detector (Agilent 1200 Series); Membrane filters of cellulose with pore size $\leq 0.45 \mu \mathrm{m}$ (Agilent); Balances with 2 and 4 decimal places (Sartorius); Refrigerators with freezer (Samsung); Common laboratory accessories. Sampling and sample treatments Sampling were done during September-October 2018 season. The samples of fresh bee honey from B\&H (Table 1), of different geographical and biological origin, were sampled in the quantities of $\geq 200 \mathrm{~g}$. Samples are being sampled by individual honey producers in glass packaging immediately after the harvesting. In a short time, they were delivered to the laboratory and immediately tested or stored in a dark place at about $20^{\circ} \mathrm{C}$ until their testing was performed [1]. Laboratory analyses are made in three parallel determination of the same sample of honey. Sample preparation procedure Before the analysis was starting, the honey sample packaging

Table 1: Geographical origin and type of honey.

\begin{tabular}{|c|c|c|c|}
\hline Ordinal No. & Geographical Area & Type of Honey & Sample Mark \\
\hline 1. & Svilaj & accacia & 704 \\
\hline 2. & Trnovo & chestnut & 790 \\
\hline 3. & Velika Kladuša & accacia & 825 \\
\hline 4. & Konjic & accacia & 832 \\
\hline 5. & Gradačac & honeydew & 824 \\
\hline 6. & Sarajevo & honeydew & 836 \\
\hline 7. & Sokolac & accacia & 841 \\
\hline 8. & Konjic & accacia & 852 \\
\hline 9. & Gradačac & meadow & 866 \\
\hline 10. & Gradačac & meadow & 870 \\
\hline 11. & Kakanj & meadow & 872 \\
\hline 12. & Goražde & accacia & 881 \\
\hline 13. & Goražde & chestnut & 885 \\
\hline 14. & Cazin & flower honey & 886 \\
\hline 15. & Cazin & honeydew & 887 \\
\hline 16. & Cazin & chestnut & \\
\hline 17. & Cazin & & \\
\hline
\end{tabular}




\section{International Journal of Environmental Sciences \& Natural Resources}

\begin{tabular}{|c|c|c|c|}
\hline 18. & Cazin & meadow & 888 \\
\hline 19. & Cazin & accacia & 890 \\
\hline 20. & Goražde & accacia & 868 \\
\hline 21. & Cazin & heather & 893 \\
\hline
\end{tabular}

a) Interferences: It was found that in the retention time interval of HMF (Rt $=3.05 \pm 7 \%$ ) there are no peaks, in which has proven that there is no interference which the source could be the contamination.

b) Specificity (selectivity): For determining specificity, a sample of acacia was used, which is sampled in the geographic area of Svilaj (B \& H, from 7.5.2018), by the laboratory employees, with the assumption that there are no traces of HMF because it is completely fresh bee honey. Except for the traces of HMF that were determined there were no other signals that pose a nuisance. The peak for this sample which occurs before the HMF has a satisfactory value of selectivity and does not perturbation.

c) Limit of detection (LOD): The calculated results $(0.272 \mathrm{mAU})$ of the LOD obtained by formula LOD $=X+3 \mathrm{SD}$; where is $X$ - average of signal and SD - its standard deviation, and the experimentally obtained by signal to noise $(\mathrm{S} / \mathrm{N})$ ratio $(0.282 \mathrm{mAU})$ are agreed with more than $96 \%$. It was great confirmation for LOD.

d) Limit of quantification (LOQ): To prove the LOQ concentration, a blind sample was used in 6 parallel samples, spiked with $6 \mathrm{ng} / \mathrm{mL}$ HMF (equivalence by sample $60 \mathrm{ng} / \mathrm{g}$ of HMF). Statistical results obtained $(X=0.740 ; \mathrm{SD}=0.018$ and RSD $=2.384$ ). The LOQ value is experimentally verified by two analysts (Table 2).

Table 2: Mean results values of $L O Q$.

\begin{tabular}{|c|c|c|}
\hline Concentration / Signal & Months & Analiyst \\
\hline $0,006 \mathrm{mg} / \mathrm{kg} / 2,33 \mathrm{mAU}$ & Maj/juni 2018 & first \\
\hline $0,006 \mathrm{mg} / \mathrm{kg} / 2,74 \mathrm{mAU}$ & Septembar 2018 & second \\
\hline
\end{tabular}

e) Linearity: Linearity is determined in the area of LOQ value $(6 \mathrm{ng} / \mathrm{mL}$-corresponds to $60 \mathrm{ng} / \mathrm{g})$ to the point of interest prescribed by law $(10 \mu \mathrm{g} / \mathrm{mL}$ - subject to $100 \mu \mathrm{g} / \mathrm{g})$. Namely, according to the regulation for the quality control of honey and other bee products (Official. Gazette, No. 37/09) in B\&H, MRL for $\mathrm{HMF}$ is $40 \mathrm{mg} / \mathrm{kg}$ and for honey from the area of Ecuador MRL is $80 \mathrm{mg} / \mathrm{kg}$. Aqueous solutions of HMF standard were used for linearity determination which is established at 5 points of concentration: $6 \mathrm{ng} / \mathrm{mL}, 2 \mu \mathrm{g} / \mathrm{mL}, 4 \mu \mathrm{g} / \mathrm{mL}, 8 \mu \mathrm{g} / \mathrm{mL}$, and $10 \mu \mathrm{g} / \mathrm{mL}$. Each point is measured three times. High accuracy of the results was obtained with a coefficient of correlation $r^{2}=0,99999$. The results are verified by two analysts in the laboratory conditions where is $\mathrm{SD}<1.10$ and $\mathrm{RSD}<0.65$ of all measurements.

f) Precision: Precision is validated as internal laboratory precision, by the same method in the same conditions by the two analysts at different times. Precision was verified on three concentration levels of the measuring range of the method: $60 \mathrm{ng} / \mathrm{g}, 40 \mu \mathrm{g} / \mathrm{g}$ and $100 \mu \mathrm{g} / \mathrm{g}$ (Table 3).

Table 3: Results of precission for $6 \mathrm{ng} / \mathrm{mL}$ respectively $60 \mathrm{ng} / \mathrm{g}, 4 \mu \mathrm{g} / \mathrm{mL}$ respectively $40 \mu \mathrm{g} / \mathrm{g}$ i $10 \mu \mathrm{g} / \mathrm{mL}$ respectively $100 \mu \mathrm{g} / \mathrm{g}$ gives as area.

\begin{tabular}{|c|c|c|c|c|}
\hline \multirow{2}{*}{ Analyst } & Value & $\mathbf{6 n g} / \mathbf{m L} \mathbf{( m A U )}$ & $\mathbf{4} \boldsymbol{\mu g} / \mathbf{m L}(\mathbf{m A U})$ & $\mathbf{1 0} \boldsymbol{\mu g} / \mathbf{m L}(\mathbf{m A U})$ \\
\hline \multirow{3}{*}{ First } & $\bar{X}$ & 10,408 & 571,950 & $1,399,852$ \\
\cline { 2 - 5 } & $\mathrm{SD}$ & 0,099 & 0,849 & 1,485 \\
\cline { 2 - 5 } & $\mathrm{RSD}$ & 0,953 & 0,148 & 0,106 \\
\hline \multirow{3}{*}{ Second } & $\bar{X}$ & 11,439 & 574,345 & $1,447,915$ \\
\cline { 2 - 5 } & $\mathrm{SD}$ & 0,139 & 0,510 & 0,785 \\
\cline { 2 - 5 } & $\mathrm{RSD}$ & 1,214 & 0,089 & 0,054 \\
\hline
\end{tabular}

g) Accuracy: Accuracy was determined by calculating recovery values (R) obtained from spiked sample 304 which had only traced of HMF. These values were obtained through precision determination at three levels.

h) $\mathrm{R}$ is calculated by the formula: $\mathrm{R}=$ Ps Pbs $x 100(\%)$, where is $P s$ - area of signal from spiked sample; $P b s$ - area of signal from blank sample. The average values of peak area from the blank samples obtained in linearity validation was taken as reference values.

i) The measuring range It is determined during the validation of precision and accuracy at the spiked concentration of a calibraton curve of $6 \mathrm{ng} / \mathrm{ml}$ (corresponding to $60 \mathrm{ng} / \mathrm{g}$ ), $4 \mathrm{mg} /$ $\mathrm{mL}$ (corresponding to $40 \mu \mathrm{g} / \mathrm{g}$ ) and $10 \mathrm{mg} / \mathrm{mL}$ (corresponding to $100 \mu \mathrm{g} / \mathrm{g}$ ). Based on the results obtained in precision and accuracy tests by two analysts, it has been confirmed that the measuring range of this method is within an interval from $60 \mu \mathrm{g} /$ $\mathrm{kg}$ to $\geq 100 \mathrm{mg} / \mathrm{kg}$ (Table $2 \& 3$ ). Obtained average recovery values from $92 \%-102 \%$ with a very small standard deviation around MRL value of HMF shows very good behavior. Individual $R$ value at the LOQ concentration of HMF varies over a somewhat broader range $(66 \%-146 \%)$, which could be expected in routine analyses perform. The individual values of the obtained accuracy results for the whole area vary from $73-120 \%$ (Table 4 ). 
Table 4: Results of accuracy for $6 \mathrm{ng} / \mathrm{mL}$ respectively $60 \mathrm{ng} / \mathrm{g}, 4 \mu \mathrm{g} / \mathrm{mL}$ respectively $40 \mu \mathrm{g} / \mathrm{g}$ i $10 \mu \mathrm{g} / \mathrm{mL}$ respectively $100 \mu \mathrm{g} / \mathrm{g}$ gives as area. $\bar{R}$-the average value of recovery.

\begin{tabular}{|c|c|c|c|c|}
\hline Analyst & Value & $\mathbf{6 n g} / \mathbf{m L}$ & $\mathbf{4} \boldsymbol{\mu g} / \mathbf{m L}$ & $\mathbf{1 0} \boldsymbol{\mu g} / \mathbf{m L}$ \\
\hline \multirow{3}{*}{ First } & $\overline{\mathrm{R}}(\%)$ & 102 & 98 & 96 \\
\cline { 2 - 5 } & $\mathrm{SD}$ & 2,71 & 0,171 & 0,117 \\
\cline { 2 - 5 } & $\mathrm{RSD}$ & 2,69 & 0,124 & 0,078 \\
\hline \multirow{3}{*}{ Second } & $\mathrm{R}(\%)$ & 99 & 92 & 101 \\
\cline { 2 - 5 } & $\mathrm{SD}$ & 23,41 & 0,029 & 0,053 \\
\cline { 2 - 5 } & $\mathrm{RSD}$ & 23,18 & 0,025 & 0,039 \\
\hline
\end{tabular}

j) Measuring uncertainty The standard measuring uncertainty is calculated from intralaboratory results obtained in precision and accuracy validation at the three next concentration $60 \mathrm{ng} / \mathrm{g}, 40 \mu \mathrm{g} / \mathrm{g}$ and $100 \mu \mathrm{g} / \mathrm{g}$. The total measuring uncertainty is calculated by the formula: uc $=\sqrt{\text { uprecision } 2}+u \_$bias $2+$ uother sources 2 Extended measurement uncertainty was calculated for $\mathrm{k}=2$ and had the following values: $5.56 \%$ for $60 \mathrm{ng} / \mathrm{g}, 0.80 \%$ for $40 \mu \mathrm{g} / \mathrm{g}$ and $5.11 \%$ for $100 \mu \mathrm{g} / \mathrm{g}$. Other sources of measurement uncertainty were not taken into account because the bias included all accidental errors, on the other hand, the standard uncertainties of the measuring and control equipment, CRM as well as the reagents were statistically less significant compared to the bias and measurement accuracy.

k) An inter-laboratory comparative study - proficiency testing: An inter-laboratory comparative study of the HMF content of honey was conducted in 2017 with a $\mathrm{z}$-score $=+1.6$. The result obtained was $86.03 \mathrm{mg} / \mathrm{kg}$ and the target value were $76.1 \mathrm{mg} / \mathrm{kg}$. A satisfactory PT in December 2017 (FAPAS provider) was the final proof of the method's success. RESULTS AND DISCUSSION The testing results of HMF content in honey samples from different geographical areas of B\&H (Table 1) show that they are in accordance with international regulations [1]. Seven samples were taken from the same geographical area (Cazin), of which two were chestnuts, and one was a sample of flower, honeydew, heather and acacia honey.

Approximate amounts of HMF were found in acacia honey (890) and flower honey (885), while traces were found in other samples. Three samples were taken from the Goražde region, two of them were acacia and one of the meadows. In accacia samples (872 and 868) found an approximate content of HMF and traces were found in meadow honey. Three samples were taken from the Gradačac region, of which two were acacia (832 and 842) and one meadow honey (852). HMF content was relatively low in acacia samples, but significantly different, while in the meadow honey sample the HMF content of $27.4 \mathrm{mg} / \mathrm{kg}$ was the highest of all samples tested (Figure 1). Two honey samples (825 and 841) were taken from the Konjic region, in both of them were relatively low HMF content. Samples of different varieties, acacia, honeydew, chestnut and meadow $(304,761,790,824,836,866)$ were collected from the area of Svilaj, Trnovo, Velika Kladuša, Sarajevo, Sokolac and Kakanj (Table 1), respectively. Approximate values of HMF were found in the samples of honeydew (824 and 836) and meadow honey (866) and are significantly higher than other values from these localities.

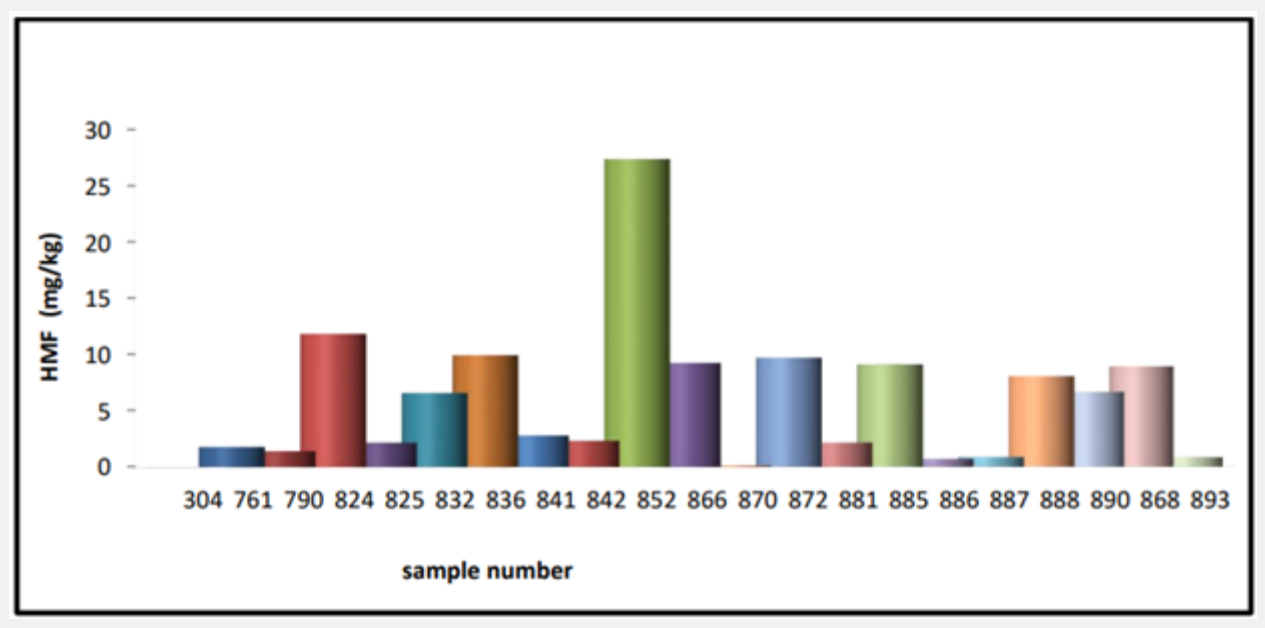

Figure 1: HMF content in fresh bee honey produced in B\&H in 2018.

The results show that the content of HMF in fresh B\&H honey does not differ significantly with respect to variety or geographical origin (Table 1 \& Figure 1). Specifically, variation in results in HMF content probably depends on climatic conditions, processing or feeding of bees [3], but we did not determine reasons because this was not the aim of the study. In our study it was shown that it was not possible to take a sample without HMF content even on the apiary itself (Svilaj, acacia honey, sample code 304). The results obtained from testing fresh honey samples show a correlation with studies done in the world [3]. 


\section{Conclusion}

The results of the method validation in this paper prove that the validation of the HMF content in honey by the HPLC DAD method can be successfully validated in the own laboratory's conditions by modifying certain conditions over standard methods [1].

Specifically, in this method used settling and double filtration to remove ballast matter in honey but did not affect the validation results. Test results of 21 samples of fresh B\&H honey of different biological and geographical origin ( 8 accacia, 4 honey, 3 chestnut, 4 meadow, 1 flower and 1 heather) range from $0.02 \mathrm{mg} / \mathrm{kg}$ (acacia honey) to $27,40 \mathrm{mg} / \mathrm{kg}$ (meadow) and are well below the legally prescribed MRL value of $40 \mathrm{mg} / \mathrm{kg}$. In seven samples, the HMF content was less than $2 \mathrm{mg} / \mathrm{kg}$ (1 acacia, 2 honeydew, 2 chestnut, 1 heather and 1 meadow). For three acacia and one chestnut samples, the HMF content is less than $3 \mathrm{mg} / \mathrm{kg}$. In 10 samples, the HMF content ranges from $6-10 \mathrm{mg} / \mathrm{kg}$ ( 4 accacia 3 meadows and 1 honeydew). According to the testing results of HMF content in fresh B\&H honey, it can be concluded that is highly recommended and safe for consumption regardless of the type of honey or geographical origin. Remark: The results obtained in this work were statistically processed using Microsoft Excel 2007 and SPSS statistics.

\section{Acknowledgment}

For this manuscript sample collection and laboratory analysis were done by funding Federal Institute of Agriculture Sarajevo. All procedures performed in these studies involving human participants were in accordance with the ethical standards of the institutional and national research standards and with the 1964 Helsinki declaration and its later amendments or comparable world ethical standards. Additional informed consent was obtained from all individual participants for whom identifying information is included in this article. All authors of this manuscript Harun Kurtagić, Edita Sarić, Nevzeta Abdelfattah and Nađa Muratbegović declares that they have no conflict of interest given in disclosure of potential conflict of interest in instruction for authors of this Journal.

\section{References}

1. Harmonised Methods of the International Honey Commission (2009).
2. Lewkowski J (2001) Synthesis, chemistry and applications of 5-hydroxymethylfurfural and its derivatives. ARKIVOC 2001(1): 17-54.

3. PM da Silva PM, Gauche C, Gonzaga LV, Costa ACO, Fett R (2016) Honey: Chemical composition, stability and authenticity. Food Chemistry 196: 309-323.

4. L Vorlová, I Borkovcová, K Kalábová, V Večerek, (2006) Hydroxymethylfurfural contents in foodstuffs determined by HPLC method. Journal of Food and Nutrition Research 45(1) 34-38.

5. Shapla UM, Solayman M, Alam N, Khalil MI, Gan SH (2018) 5-Hydroxymethylfurfural (HMF) levels in honey and other food products: Effects on bees and human health. Chemistry Central Journal 12(1): 35.

6. Ruiz Matute AI, Weiss M, Sammataro D, Finely J, Sanz ML (2010) Carbohydrate composition of high-fructose corn syrups (HFCS) used for bee feeding: effect on honey composition. Journal of Agricultural and Food Chemistry 58(12): 7317-7322.

7. PubChem, 70ETD81LF0 (2019).

8. Fallico B, Arena E, Zappala M (2008) Degradation of 5hydroxymethylfurfural in honey. Journal of Food Science 73(9): C625-C631.

9. Turhan I, Tetik N, Karhan M, Gurel F, Tavukcuoglu HR (2008) Quality of honeys influenced by thermal treatment. LWT-Food Science and Technology 41(8): 1396-1399.

10. Ajlouni S, Sujirapinyokul P (2010) Hydroxymethylfurfuraldehyde and amylase contents in Australian. Food Chemistry 119(3): 1000-1005.

11.Zirbes L, Nguyen BK, de Graaf DC, De Meulenaer B, Reybroeck W, et al. (2013) Hydroxymethylfurfural: a possible emergent cause of honey bee mortality? Journal of Agricultural and Food Chemistry 61(49): 11865-11870.

12. M Zappala, B Fallico, E Arena, A Verzera (2005) Methods for the determination of HMF in honey: a comparison. Food Control 16(3): 273-277.

13. V Gökmen, HZ Senyuva (2006) Improved method for the determination of hydroxymethylfurfural in baby foods using liquid chromatographymass spectrometry. Journal of Agricultural and Food Chemistry 54(8): 2845-2849.

14. Kmecl V, Škerl MIS (2014) A comparison of two methods for determination of HMF in honey and bee food: HPLC method versus spectrophotometric Winkler method. In 49th Croatian \& 9th International Symposium on Agriculture. Croatia.

15. Makawi SZA, Taha MI, Zakaria BA, Siddig B, Mahmod H, et al. (2009) Identification and quantification of 5-hydroxymethyl furfural HMF in some sugar-containing food products by HPLC. Pakistan Journal of Nutrition 8(9): 1391-1396. 
Your next submission with Juniper Publishers will reach you the below assets

- Quality Editorial service

- Swift Peer Review

- Reprints availability

- E-prints Service

- Manuscript Podcast for convenient understanding

- Global attainment for your research

- Manuscript accessibility in different formats ( Pdf, E-pub, Full Text, Audio)

- Unceasing customer service

Track the below URL for one-step submission https://juniperpublishers.com/online-submission.php 